\title{
Inhibitory effect of the low-toxic exogenous aryl hydrocarbon receptor modulator 3'3-diindolylmethane on gastric cancer in mice
}

\author{
MINGLI SU ${ }^{*}$, CHENCHEN QIAN $^{1 *}$, YUMIN HU $^{2}$, WENHUA LU ${ }^{2}$, \\ RONGKANG HUANG ${ }^{3}$, MINHU CHEN ${ }^{1}$ and JIE CHEN ${ }^{1}$
}

\author{
${ }^{1}$ Department of Gastroenterology, The First Affiliated Hospital of Sun Yat-sen University, Guangzhou, Guangdong 510080; \\ ${ }^{2}$ Sun Yat-sen University Cancer Center, Guangzhou, Guangdong 510060; ${ }^{3}$ Department of Colorectal Surgery, \\ The Sixth Affiliated Hospital of Sun Yat-sen University, Guangzhou, Guangdong 510655, P.R. China
}

Received November 8, 2015; Accepted August 8, 2017

DOI: $10.3892 / \mathrm{ol} .2017 .7185$

\begin{abstract}
Diindolylmethane (DIM) has been proved to exhibit anticancer properties in many solid tumors. In our previous study, we demonstrated that DIM inhibited SGC7901 cell proliferation by inducing apoptosis and delaying cell cycle progression. Herein, we further explored the anti-tumor effect of DIM on SGC-7901 tumor bearing mice. Tumors were excised, weighed, and tested by western blot and TdT-UTP nick-end labeling (TUNEL) assay. Blood samples were collected for biochemical analysis. The expression levels of AhR and cytochrome P450, family 1, subfamily A, polypeptide 1 (CYP1A1) protein were evaluated by western-blot assay. Our data show that with the increase of DIM dose $(0,5,10,20 \mathrm{mg} / \mathrm{kg} /$ day $)$, AhR protein gradually decreased as CYP1A1 protein increased. The weight of the tumors found in the treated animals was significantly lower than that of the control group $(0.845 \pm 0.096$ vs. $1.275 \pm 0.236 \mathrm{~g}, 0.768 \pm 0.161$ vs. $1.275 \pm 0.236 \mathrm{~g}, 0.607 \pm 0.106$ vs. $1.275 \pm 0.236 \mathrm{~g}, \mathrm{P}<0.05)$. TUNEL test showed that DIM induced increased apoptosis in the treatment groups in a dose-dependent manner. Blood tests also indicated that DIM showed no toxic effect on animal weight or liver and kidney function. These results indicated that DIM agent could be a safe and potent drug in therapy of gastric cancer.
\end{abstract}

Correspondence to: Professor Jie Chen, Department of Gastroenterology, The First Affiliated Hospital of Sun Yat-sen University, 58 Zhongshan Er Road, Guangzhou, Guangdong 510080, P.R. China

E-mail: chen0jie@hotmail.com

*Contributed equally

Abbreviations: AhR, aryl hydrocarbon receptor; DIM, 3'3-diindolylmethane; GCa, gastric cancer; TCDD, 2,3,7,8tetrachlorodibenzo- $p$-dioxin; TUNEL, TdT-UTP nick-end labeling

Key words: gastric cancer, aryl hydrocarbon receptor, 3'3-diindolylmethane, nude-mice model

\section{Introduction}

Gastric cancer (GCa) is one of the most common types of malignancy, and the third leading cause of cancer-associated mortality worldwide, with 951,000 incident cases and 723,000 mortalities in 2012 (1). The overall 5-year survival rate is low due to high recurrence rates, nodal metastasis and poor responses to chemotherapy (2). Differences in lifestyle, environment and diet may also have a role in the high incidence and mortality associated with GCa (3). The aryl hydrocarbon receptor $(\mathrm{AhR})$ is a ligand-activated transcription factor involved in cell differentiation and carcinogenesis, including in lung cancer (4), breast cancer (5) and prostate cancer (6). There are currently few studies involving the AhR pathway and GCa (7). Our previous study demonstrated there is significant AhR expression in human GCa cells (8), and determined that the AhR agonist 2,3,7,8-tetrachlorodibenzo-p-dioxin (TCDD) could inhibit GCa cell growth (9). Thus, AhR maybe a promising target for GCa therapy. Due to the toxic and carcinogenic effects of TCDD in humans, our previous study had suggested that the selective AhR receptor modulator 3'3-diindolylmethane (DIM) could inhibit SGC-7901 human GCa cell proliferation by delaying cell cycle progression and inducing apoptosis (10). DIM is an acid-catalyzed condensation product of indole-3-carbinol, a constituent of cruciferous vegetables (11). DIM has been identified as an anti-cancer agent involved in various solid malignancies, including ovarian (12), prostate (13), colon (14) and pancreatic cancer (15). The anti-cancer effects of DIM include suppressing cancer cell proliferation (16-18) and promoting cancer cell apoptosis (19-21). There have been few reports to date regarding the effects of DIM on GCa cells, and the purpose of the present study was to examine the potential beneficial effect of DIM in the prevention of tumor development following the subcutaneous transplantation of SGC-7901 cells into mice, in addition to exploring the possible underlying mechanisms.

\section{Materials and methods}

Cell line and culture. The SGC-7901 Human gastric cancer cell line was obtained from the Cancer Institute of Chinese Academy of Medical Science (Beijing, China). SGC-7901 
cells were maintained in RPMI-1640 medium (Gibco; Thermo Fisher Scientific, Inc., Waltham, MA, USA) supplemented with $10 \%$ fetal bovine serum (HyClone; GE Healthcare Life Sciences, Logan, UT, USA), $1 \times 10^{5} \mathrm{U} / 1$ penicillin and $0.1 \mathrm{~g} / 1$ streptomycin. The cells were maintained at $37^{\circ} \mathrm{C}$ in an atmosphere containing $50 \mathrm{ml} / 1 \mathrm{CO}_{2}$.

Animal model. A total of 32 female Balb/c nude mice (4 weeks old, weight, 15-18 g) were purchased from Center of Experiment Animal of Guangdong (Guangzhou, China). The animals were housed in metal cages (4 mice/cage) and were kept in a room lit for $12 \mathrm{~h}$ per day and maintained at a temperature of $22 \pm 1^{\circ} \mathrm{C}$. Diet (purchased from Center of Experiment Animal of Guangdong, Guangzhou, China) and sterile water were given ad libitum. The mice were randomly divided into two groups, receiving castor oil $(n=8$; control) or DIM $(n=8 ; 5$, 10 or $10 \mathrm{mg} / \mathrm{kg} /$ day) respectively. Two weeks later, SGC-7901 cells ( $1 \times 10^{6}$ cells) were inoculated subcutaneously into the right upper flank of the two groups of mice and were administered castor oil or DIM for another 6 weeks continuously. At the end of the experiment, all mice were sacrificed under general anesthesia by isoflurane and tumor tissues were weighed prior to collection for western blot and TdT-UTP nick-end labeling (TUNEL) assay. The body weights of mice were recorded every 4 days for 8 weeks. The tumor volumes were calculated using the formula $\mathrm{V}=\mathrm{ax} \mathrm{b}^{2} \mathrm{x} \pi / 6$, where $\mathrm{a}$ is the length, $\mathrm{b}$ is the width and $\mathrm{V}$ is the volume in $\mathrm{mm}^{3}$. In addition, blood samples were collected to evaluate liver and kidney function. The experiment was conducted in accordance with the Committee for the Supervision of Animal Experiments, the First Affiliated Hospital of Sun Yat-sen University (Guangzhou, China), who approved the study protocol.

Western blot analysis. Tissue was extracted from tumors of the control and treated mice, and then lysed in buffer $(20 \mathrm{mmol} / \mathrm{l}$ HEPES, $1 \mathrm{mmol} / 1$ EGTA, $50 \mathrm{mmol} / 1 \beta$-glycerophosphate, $2 \mathrm{mmol} / \mathrm{l}$ sodium orthovanadate, $100 \mathrm{ml} / 1$ glycerol, $10 \mathrm{ml} / 1$ Triton X-100, $1 \mathrm{mmol} / \mathrm{l}$ DTT, and $1 \mathrm{X}$ protease inhibitor cocktail; Roche Diagnostics, Mannheim, Germany). The lysate was centrifuged $(18,894 \mathrm{x} \mathrm{g})$ at $4^{\circ} \mathrm{C}$ for $10 \mathrm{~min}$. The supernatant was the total cell lysate. Protein concentration was measured using a BCA protein assay kit (Pierce; Thermo Fisher Scientific, Inc.). Protein $(30 \mu \mathrm{g})$ was loaded into each lane, separated by $10 \%$ SDS-PAGE and transferred onto an equilibrated polyvinylidene difluoride membrane via electroblotting. Membranes were blocked with 5\% non-fat milk in $1 \%$ TBS-T buffer for $2 \mathrm{~h}$ at room temperature. AhR, cytochrome P450, family 1 , subfamily A, polypeptide 1 (CYP1A1) and GAPDH were detected for $2 \mathrm{~h}$ using antibodies against AhR (\#SC-5579; dilution, 1:150; Santa Cruz Biotechnology, Inc., Dallas, TX, USA), CYP1A1 (\#AB1258; dilution, 1:500; Chemicon International, Inc., Temecula, CA, USA) and GAPDH (\#2118; dilution, 1:1,000; Cell Signaling Technology, Inc.). After secondary antibodies (goat anti-rabbit IgG antibody, \#7074 and goat anti-rat IgG antibody, \#7077; dilution, 1:2,000; Cell Signaling Technology, Inc.) incubation for $2 \mathrm{~h}$, protein bands were detected using an ECL system (Pierce; Thermo Fisher Scientific, Inc.). Densitometry analysis was performed using Quantity One software (version 4.62; Bio-Rad Laboratories, Inc., Hercules, CA, USA) and analyzed them using.
TdT-UTP nick end labeling (TUNEL) assay. The TUNEL assays were performed using the one-step TUNEL kit (\#KGA7072; Nanjing KeyGEN, Inc., Nanjing, China) according to the manufacturer's instructions. The paraffin-embedded tissue sections were dewaxed with dimethylbenzene for $15 \mathrm{~min}$ at $37^{\circ} \mathrm{C}$, dehydrated via an alcohol gradient for $20 \mathrm{~min}$ at $37^{\circ} \mathrm{C}$, and then permeabilized using $0.1 \%$ Triton $\mathrm{X}-100$ for $8 \mathrm{~min}$ on ice, followed by TUNEL for $1 \mathrm{~h}$ at $37^{\circ} \mathrm{C}$. The fluorescein isothiocyanate-labeled TUNEL-positive cells were imaged under a fluorescent microscope (magnification, x200) at an excitation wavelength of 450-500-nm and emission wavelength of 515-565-nm. The cells with green fluorescence were defined as apoptotic cells. The percentage of TUNEL-positive cells from images of 10 randomly selected fields in each group was identified.

Biochemical analysis. All biochemical analyses were performed according to an automated procedure at the Department of Biochemistry, the First Affiliated Hospital of Sun Yat-sen University (Guangzhou, China). Assays of white blood cells (WBC), hemoglobin (HB), platelets (PLT) in the blood samples were performed using a Sysmex XS-1000i analyzer (Sysmex Shanghai Ltd., Shanghai, China). Serum glutamic oxaloacetic transaminase (SGOT), serum glutamic pyruvic transaminase (SGPT), creatinine and urea were assessed using a Beckman-Coulter AU5800 analyzer (Beckman Coulter, Inc., Brea, CA, USA).

Statistical analysis. Data are presented as the mean \pm standard deviation. Statistical analysis of the data was performed using one-way analysis of variance and the Student-Newman-Keuls test with the SPSS statistical software package (version 11.0; SPSS, Inc., Chicago, IL, USA). P<0.05 was considered to indicate a statistically significant difference.

\section{Results}

DIM activates the AhR pathway. As DIM is a selective AhR receptor modulator, and our previous study had suggested that DIM could inhibit human GCa cell (SGC-7901) proliferation by delaying cell cycle progression and inducing apoptosis, at the end of the experiment the mice were sacrificed under general anesthesia by isoflurane and the tumor tissue proteins were evaluated via western blotting to determine whether the AhR signaling pathway could be activated by DIM. The results indicated that AhR protein expression gradually decreased and that the levels of CYP1A1 were increased in a dose-dependent manner following DIM treatment (Fig. 1).

Effect of DIM on tumor development. The 8 mice in each group were pretreated for 2 weeks via gavage of three doses $(5,10$ and $20 \mathrm{mg} / \mathrm{kg} /$ day) of DIM. These doses were selected according to other published articles $(19,22,23)$. On week 2, tumors were initiated by transplanting SGC-7901 cells subcutaneously into the flanks of the mice. Graphical representation of the changes in tumor volume/body weight with time (Fig. 2A) revealed that the tumor volume of the DIM-treated groups increased more slowly than that of the control group. The weights of the tumors presented 
Table I. Liver and kidney function in the various groups.

DIM

\begin{tabular}{lccccccc}
\cline { 5 - 8 } Test & Control & $5 \mathrm{mg} / \mathrm{kg} / \mathrm{day}$ & P-value & $10 \mathrm{mg} / \mathrm{kg} / \mathrm{day}$ & P-value & $20 \mathrm{mg} / \mathrm{kg} / \mathrm{day}$ & P-value \\
\hline WBC $\left(10^{9} / \mathrm{l}\right)$ & $4.25 \pm 1.14$ & $3.66 \pm 1.13$ & 0.32 & $3.66 \pm 1.11$ & 0.31 & $3.39 \pm 0.81$ & 0.14 \\
Hemoglobin $(\mathrm{g} / \mathrm{l})$ & $164.75 \pm 8.41$ & $159.75 \pm 7.55$ & 0.23 & $164.38 \pm 5.48$ & 0.92 & $158.83 \pm 8.54$ & 0.22 \\
Platelet $\left(10^{9} / \mathrm{l}\right)$ & $133.50 \pm 94.24$ & $132.50 \pm 115.56$ & 0.99 & $250.38 \pm 200.11$ & 0.16 & $227.00 \pm 179.04$ & 0.23 \\
SGOT (U/l) & $228.50 \pm 60.54$ & $246.75 \pm 95.48$ & 0.69 & $233.00 \pm 77.99$ & 0.91 & $195.00 \pm 20.74$ & 0.27 \\
SGPT (U/l) & $92.50 \pm 107.46$ & $55.00 \pm 12.71$ & 0.34 & $62.50 \pm 6.02$ & 0.51 & $52.00 \pm 19.43$ & 0.43 \\
Urea (mmol/l) & $6.33 \pm 0.55$ & $7.24 \pm 1.96$ & 0.30 & $7.35 \pm 1.10$ & 0.07 & $6.82 \pm 0.97$ & 0.32 \\
Creatinine & $22.50 \pm 5.13$ & $23.75 \pm 7.57$ & 0.73 & $25.43 \pm 7.41$ & 0.43 & $19.00 \pm 5.15$ & 0.29 \\
$(\mu$ mol/l) & & & & & & &
\end{tabular}

There were no significant differences in the levels of WBC, hemoglobin, platelet, SGOT, SGPT, urea or creatinine as assessed by blood tests of the control and the DIM-treated groups [P>0.05 in the DIM-treated groups (5, 10 or $20 \mathrm{mg} / \mathrm{kg} /$ day $)$ vs. control group]. DIM, 3'3-diindolylmethane; WBC, white blood cells; SGOT, serum glutamic oxaloacetic transaminase; SGPT, serum glutamate pyruvate transaminase.
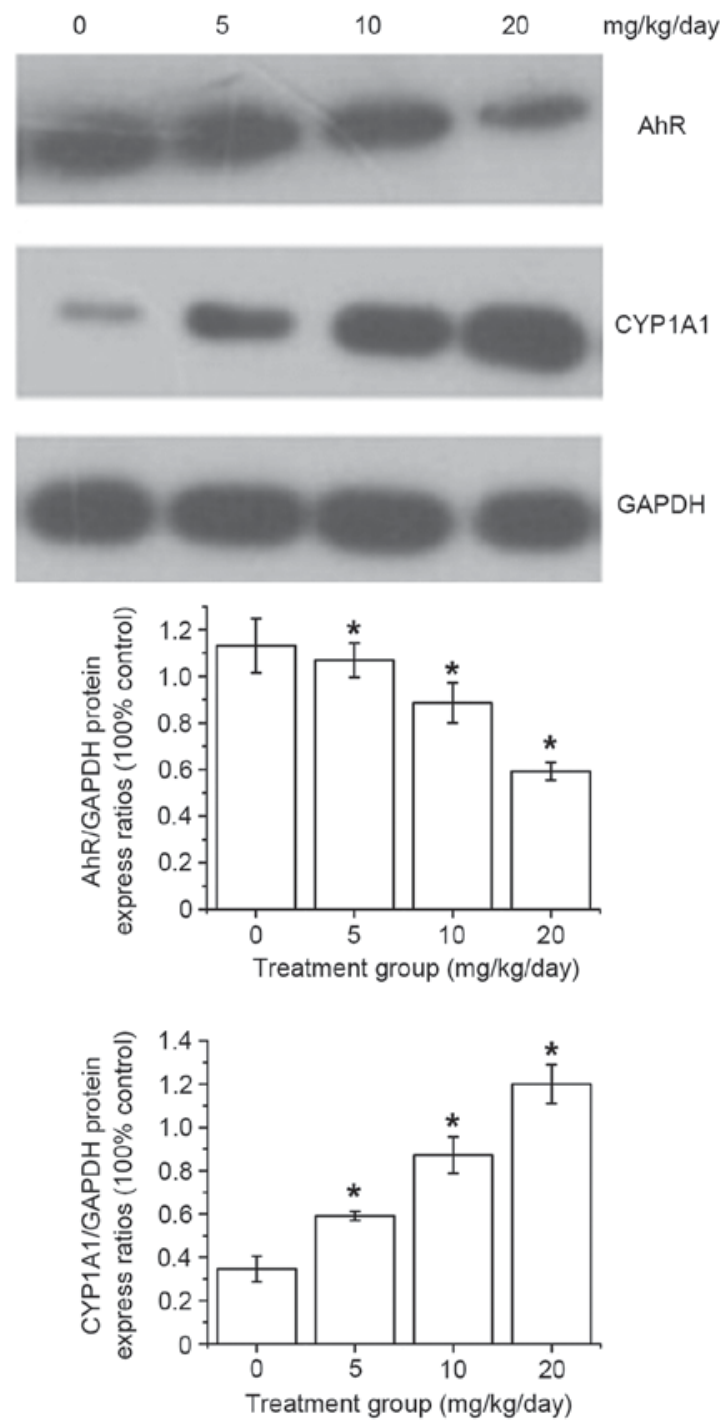

Figure 1. AhR and CYP1A1 expression in the SGC-7901 tumors of Balb/c mice following DIM treatment. After DIM treatment with $0,5,10$ or $20 \mathrm{mg} / \mathrm{kg} / \mathrm{day}$ DIM, AhR protein expression decreased and the levels of CYP1A1 increased dose-dependently. ${ }^{*} \mathrm{P}<0.05$ in the DIM-treated groups $(5,10$ or $20 \mathrm{mg} / \mathrm{kg} / \mathrm{day})$ vs. control group. AhR, aryl hydrocarbon receptor; DIM, 3'3-diindolylmethane; CYP1A1, cytochrome P450, family 1, subfamily A, polypeptide 1.
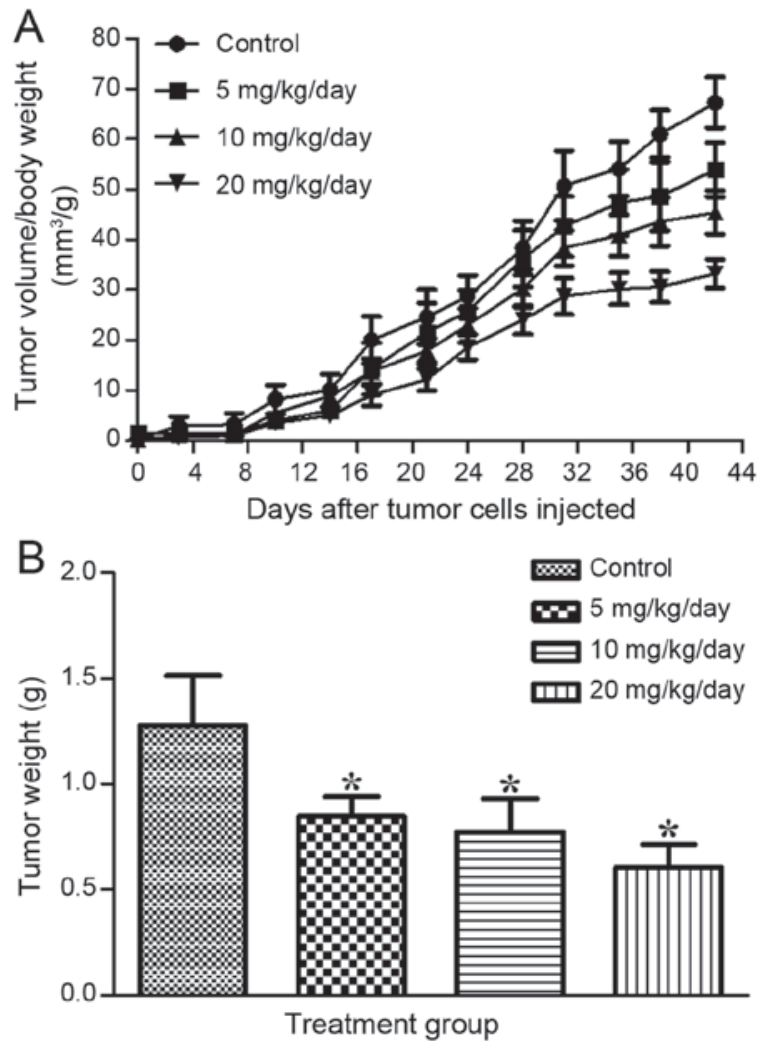

Figure 2. Effect of DIM on tumor volume and final tumor weight. (A) The changes in tumor volume/body weight with time; (B) The final tumor weight. The tumor volumes were calculated using the formula $\mathrm{V}=\mathrm{ax} \mathrm{b}^{2} \mathrm{x} \pi / 6$, where $a$ is the length, $b$ is the width and $V$ is the volume in $\mathrm{mm}^{3}$. At the end of the experiment, all mice were sacrificed and tumor tissues were weighed. The volume and weight of the tumors in the DIM-treated mice were significantly lower than those in the control group. "P<0.05. DIM, 3'3-diindolylmethane.

in the treated groups were $0.845 \pm 0.096,0.768 \pm 0.161$ and $0.607 \pm 0.106 \mathrm{~g}$ for 5,10 and $20 \mathrm{mg} / \mathrm{kg} / \mathrm{day}$, respectively, which was significantly lower than that observed in the control group (1.275 \pm 0.236 g; Fig. 2B). The results indicated that DIM significantly suppressed tumor development in the mice treated with higher concentrations. 

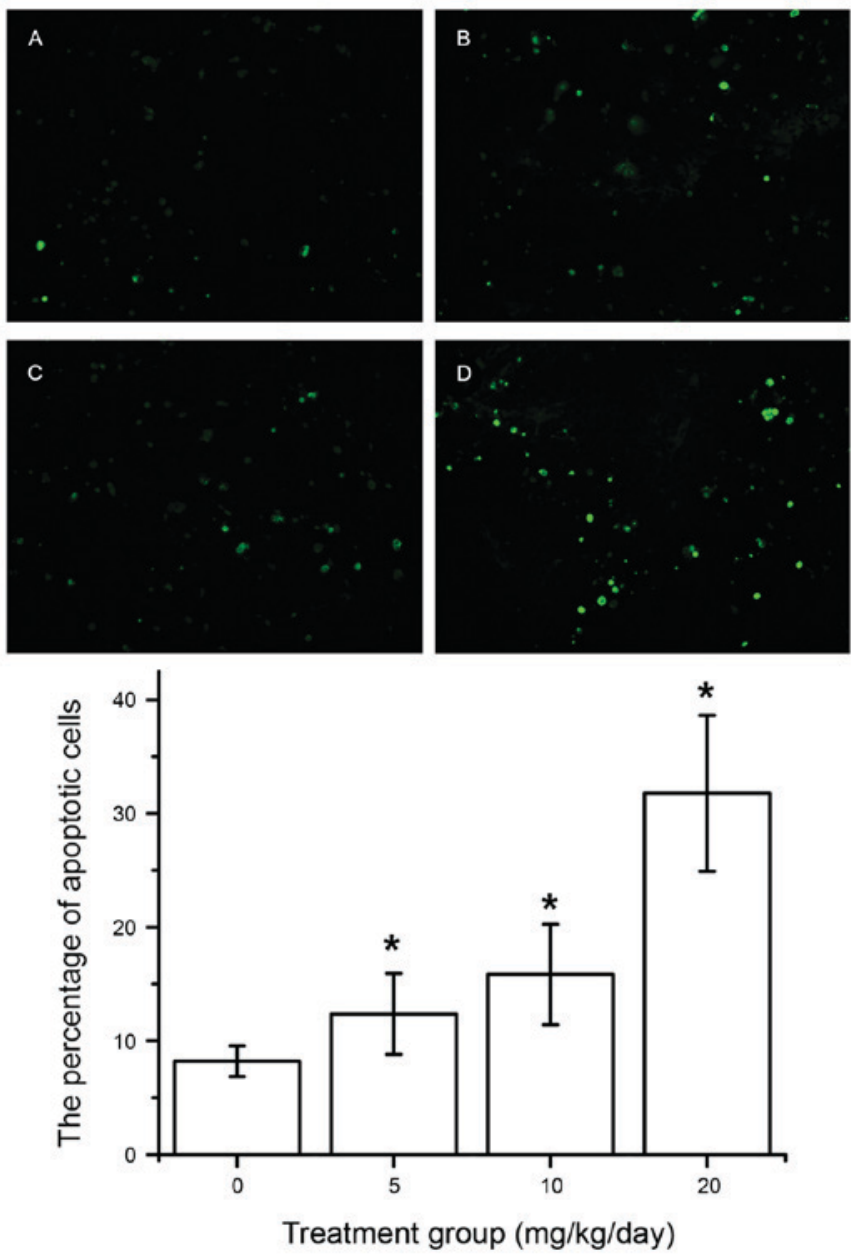

Figure 3. The effect of DIM on SGC-7901 cancer cell apoptosis in Balb/c mice. (A) Control group; (B) DIM $5 \mathrm{mg} / \mathrm{kg} / \mathrm{day}$; (C) DIM $10 \mathrm{mg} / \mathrm{kg} / \mathrm{day}$; (D) DIM $20 \mathrm{mg} / \mathrm{kg} / \mathrm{day}$. At the end of the experiment, the tumors were separated and subjected to TUNEL analysis. The number of TUNEL-positive cells was significantly increased in the treated group (DIM 5,10 or $20 \mathrm{mg} / \mathrm{kg} /$ day) compared with in the control group. "P<0.05. DIM, 3'3-diindolylmethane; TUNEL, TdT-UTP nick-end labeling.

Effect of DIM on cell apoptosis. The mechanism underlying the inhibition of tumor cell viability was further studied by evaluating the apoptotic effects of various treatments using a TUNEL assay. It was identified that DIM can markedly induce apoptosis in SGC-7901 tumor cells. Additionally, the level of apoptosis among SGC-7901 tumor cells increases in a dose-dependent manner. The data are presented in Fig. 3A-E.

Effect of DIM on the weight and biochemical state of the mice. The weights of the mice were measured every 4 days during the experiment. It was identified that treatment of the mice with DIM via gavage for 8 weeks had no significant effect on animal weight (Fig. 4). The data also indicated that DIM has no notable effect on liver or kidney function, as determined by quantifying WBC, HB, PLT, SGOT, SGPT, creatinine and urea in the blood samples (Table I).

\section{Discussion}

DIM is an anticancer agent present in cruciferous vegetables. It has been reported that DIM can modulate the expression of

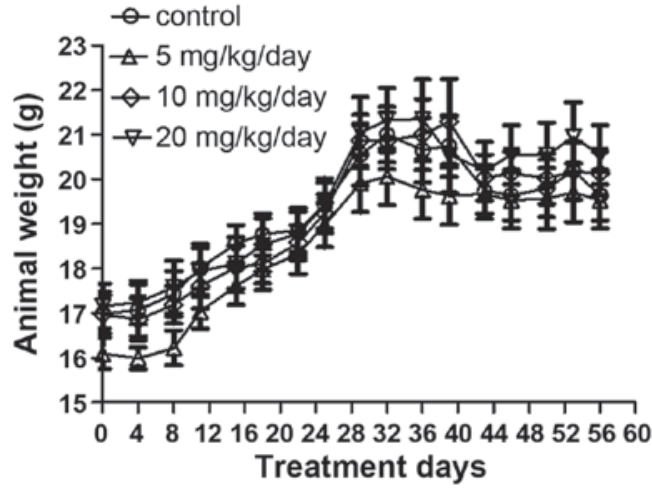

Figure 4. The effect of DIM on the weight of Balb/c mice. During the experiment, DIM treatment $(5,10$ or $20 \mathrm{mg} / \mathrm{kg} /$ day $)$ had no significant effect on animal weight. DIM, 3'3-diindolylmethane.

VEGF, IL-8, uPA and MMP-9 through inhibiting the NF- $\mathrm{BB}$ pathway in prostate cancer cells, suggesting an inhibitory effect on cancer cell proliferation (24). Jin (25) reported that the growth of MCF-7 breast cancer cells could be inhibited by downregulating the expression of Cdc25A. Our previous study determined that DIM activates the AhR pathway and induces the expression of CYP1A1 in human GCa cells (SGC-7901), which results in the inhibition cell proliferation, delaying of cell cycle progression and the induction of cell apoptosis in vitro (10). Based on this prior study, the inhibitory effect of DIM was evaluated using the SGC-7901 mouse model.

Herein, a subcutaneously transplanted SGC-7901 mouse model was developed. Western blot analysis revealed that AhR protein was gradually decreased and the protein expression of CYP1A1 was increased in a dose-dependent manner following DIM treatment (Fig. 1) (26). As a classic target gene of the AhR pathway, CYP1A1 was selected as an indicator of AhR signal pathway activation. In the current study, the expression of CYP1A1 was significantly increased in a dose-dependent manner following DIM treatment, indicating AhR pathway activation. It has been established by numerous prior studies that the AhR is a ligand-dependent transcription factor and is retained in the cytoplasm in an inactive form. Upon ligand binding, AhR is presumed to undergo a conformational change that exposes certain nuclear localization sequences, resulting in the translocation of the complex into the nucleus and subsequently activating downstream gene expression. Consequently, the results suggested that DIM modulates the AhR pathway and causes the translocation of AhR from the cytoplasm to the nucleus.

The anticancer effects of DIM include not only the inhibition of cell proliferation, but also the induction of apoptosis. It has been verified that DIM can induce apoptosis in colon (19), breast $(20)$, pancreatic $(21,22)$ and lung cancer cells $(27)$, among other types. In prostate cancer cells, DIM inhibits the AKT signaling pathway and induces cell apoptosis (28). In breast cancer cell lines with high expression of uPA/uPAR, the anticancer effects of DIM involve the inhibition of the uPA/uPAR pathway. Furthermore, DIM also induces apoptosis

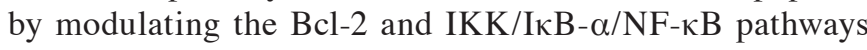
in nasopharyngeal cancer cells. (29). To further explore the apoptosis-promoting effects of DIM in GCa, cell apoptosis was assessed using a TUNEL assay. The results demonstrated 
that the number of TUNEL-positive cells was significantly increased in the treated group (DIM 5, 10 or $20 \mathrm{mg} / \mathrm{kg} / \mathrm{day}$ ) compared with in the control group (Fig. 3), suggesting that DIM can promote GCa cell apoptosis.

Additionally, the volume and weight of the tumors in the DIM-treated mice were significantly lower than those in the control group (Fig. 2). The AhR pathway serves an important role in the proliferation and invasion of GCa. Our prior study determined that TCDD could also suppress the growth of GCa cells (9), while TCDD itself is carcinogenic and toxic. Compared with TCDD, DIM may be a safer and more potent drug. However, there have been few studies to date regarding the safety of oral DIM. Roh et al (30) reported that there may be gastrointestinal toxicity associated with oral DIM in neonatal mice, due to it inhibiting the elimination of rotavirus. The results of the present study indicated that DIM has no toxic effect on body weight or liver and kidney function in mice (Fig. 4; Table I).

However, the current study neglected to measure the actual concentrations of DIM in the blood and tissues of the mice treated with DIM $(0-20 \mathrm{mg} / \mathrm{kg} / \mathrm{day})$. Anderton et al (31) developed a PBPK model to characterize the pharmacokinetic properties of DIM, and the plasma pharmacokinetics and biodistribution of DIM following oral administration, in mice (31). Future studies are required to determine the serum DIM concentrations in mice fed various doses of DIM. Combined, the data demonstrated that DIM can promote the apoptosis of GCa cells via the downregulation of AhR and the increased expression of CYP1A1. Exposure to DIM produced no observable toxicity with regard to animal weight, liver or kidney function. Thus, the results indicate that DIM could be a promising therapeutic drug for gastric cancer in the future. However, this study was limited to only one cell line, SGC-7901, and the mechanisms underlying the effects of DIM on GCa cell apoptosis still require further study.

\section{Acknowledgements}

The present study was supported by the National Natural Science Foundation of China (grant no. 81072048).

\section{References}

1. Ferlay J, Soerjomataram I, Dikshit R, Eser S, Mathers C, Rebelo M, Parkin DM, Forman D and Bray F: Cancer incidence and mortality worldwide: Sources, methods and major patterns in GLOBOCAN 2012. Int J Cancer 136: E359-E386, 2015.

2. Hartgrink HH, Jansen EP, van Grieken NC and van de Velde CJ: Gastric cancer. Lancet 374: 477-490, 2009.

3. Zabaleta J: Multifactorial etiology of gastric cancer. Methods Mol Biol 863: 411-435, 2012.

4. Su JM, Lin P, Wang CK and Chang H: Overexpression of cytochrome P450 1B1 in advanced non-small cell lung cancer: A potential therapeutic target. Anticancer Res 29: 509-515, 2009.

5. Schlezinger JJ, Liu D, Farago M, Seldin DC, Belguise K, Sonenshein GE and Sherr DH: A role for the aryl hydrocarbon receptor in mammary gland tumorigenesis. Biol Chem 387: 1175-1187, 2006

6. Fritz WA, Lin TM, Safe S, Moore RW and Peterson RE: The selective aryl hydrocarbon receptor modulator 6-methyl-1,3,8-trichlorodibenzofuran inhibits prostate tumor metastasis in TRAMP mice. Biochem Pharmacol 77: 1151-1160, 2009.

7. Yin XF, Chen J, Mao W, Wang YH and Chen MH: A selective aryl hydrocarbon receptor modulator 3,3'-diindolylmethane inhibits gastric cancer cell growth. J Exp Clin Cancer Res 31: 46, 2012.
8. Chen J, Röcken C, Klein-Hitpass L, Götze T, Leodolter A, Malfertheiner P and Ebert MP: Microarray analysis of gene expression in metastatic gastric cancer cells after incubation with the methylation inhibitor 5-aza-2'-deoxycytidine. Clin Exp Metastasis 21: 389-397, 2004.

9. Peng TL, Chen J, Mao W, Liu X, Tao Y, Chen LZ and Chen MH: Potential therapeutic significance of increased expression of aryl hydrocarbon receptor in human gastric cancer. World J Gastroenterol 15: 1719-1729, 2009.

10. Yin XF, Chen J, Mao W, Wang YH and Chen MH: A selective aryl hydrocarbon receptor modulator 3,3'-diindolylmethane inhibits gastric cancer cell growth. J Exp Clin Cancer Res 31: 46, 2012.

11. Chang YC, Riby J, Chang GH, Peng BC, Firestone G and Bjeldanes LF: Cytostatic and antiestrogenic effects of 2-(indol3-ylmethyl)-3,3'-diindolylmethane, a major in vivo product of dietary indole-3-carbinol. Biochem Pharmacol 58: 825-834, 1999.

12. Loganathan S, Kandala PK, Gupta P and Srivastava SK: Inhibition of EGFR-AKT axis results in the suppression of ovarian tumors in vitro and in preclinical mouse model. PLoS One 7: e43577, 2012.

13. Chen D, Banerjee S, Cui QC, Kong D, Sarkar FH and Dou QP: Activation of AMP-activated protein kinase by 3,3'-diindolylmethane (DIM) is associated with human prostate cancer cell death in vitro and in vivo. PLoS One 7: e47186, 2012.

14. Pappa G, Strathmann J, Löwinger M, Bartsch H and Gerhäuser C: Quantitative combination effects between sulforaphane and 3,3'-diindolylmethane on proliferation of human colon cancer cells in vitro. Carcinogenesis 28: 1471-1477, 2007.

15. Ali S, Banerjee S, Schaffert JM, El-Rayes BF, Philip PA and Sarkar FH: Concurrent inhibition of NF-kappaB, cyclooxygenase-2, and epidermal growth factor receptor leads to greater anti-tumor activity in pancreatic cancer. J Cell Biochem 110: 171-181, 2010.

16. Choi HJ, Lim DY and Park JH: Induction of G1 and G2/M cell cycle arrests by the dietary compound 3,3'-diindolylmethane in HT-29 human colon cancer cells. BMC Gastroenterol 9: 39, 2009.

17. Tadi K, Chang Y, Ashok BT, Chen Y, Moscatello A, Schaefer SD, Schantz SP, Policastro AJ, Geliebter J and Tiwari RK: 3,3'-Diindolylmethane, a cruciferous vegetable derived synthetic anti-proliferative compound in thyroid disease. Biochem Biophys Res Commun 337: 1019-1025, 2005.

18. Chang X, Firestone GL and Bjeldanes LF: Inhibition of growth factor-induced Ras signaling in vascular endothelial cells and angiogenesis by 3,3'-diindolylmethane. Carcinogenesis 27: 541-550, 2006.

19. Kim EJ, Shin M, Park H, Hong JE, Shin HK, Kim J, Kwon DY and Park JH: Oral administration of 3,3'-diindolylmethane inhibits lung metastasis of 4T1 murine mammary carcinoma cells in BALB/c mice. J Nutr 139: 2373-2379, 2009.

20. Ahmad A, Kong D, Wang Z, Sarkar SH, Banerjee S and Sarkar FH: Down-regulation of uPA and uPAR by 3,3'-diindolylmethane contributes to the inhibition of cell growth and migration of breast cancer cells. J Cell Biochem 108: 916-925, 2009.

21. BanerjeeS, WangZ,Kong DandSarkarFH:3,3'-Diindolylmethane enhances chemosensitivity of multiple chemotherapeutic agents in pancreatic cancer. Cancer Res 69: 5592-5600, 2009.

22. Ali S, Banerjee S, Ahmad A, El-Rayes BF, Philip PA and Sarkar FH: Apoptosis-inducing effect of erlotinib is potentiated by 3,3'-diindolylmethane in vitro and in vivo using an orthotopic model of pancreatic cancer. Mol Cancer Ther 7: 1708-1719, 2008.

23. Fares F, Azzam N, Appel B, Fares B and Stein A: The potential efficacy of 3,3'-diindolylmethane in prevention of prostate cancer development. Eur J Cancer Prev 19: 199-203, 2010.

24. Kong D, Li Y, Wang Z, Banerjee S and Sarkar FH: Inhibition of angiogenesis and invasion by 3,3'-diindolylmethane is mediated by the nuclear factor-kappaB downstream target genes MMP-9 and UPA that regulated bioavailability of vascular endothelial growth factor in prostate cancer. Cancer Res 67: 3310-3319, 2007.

25. Jin Y: 3,3'-Diindolylmethane inhibits breast cancer cell growth via miR-21-mediated Cdc25A degradation. Mol Cell Biochem 358: 345-354, 2011.

26. Mimura J, Yamashita K, Nakamura K, Morita M, Takagi TN, Nakao K, Ema M, Sogawa K, Yasuda M, Katsuki M and Fujii-Kuriyama Y: Loss of teratogenic response to 2,3,7,8-tetrachlorodibenzo-p-dioxin (TCDD) in mice lacking the Ah (dioxin) receptor. Genes Cells 2: 645-654, 1997.

27. Ichite N, Chougule MB, Jackson T, Fulzele SV, Safe S and Singh M: Enhancement of docetaxel anticancer activity by a novel diindolylmethane compound in human non-small cell lung cancer. Clin Cancer Res 15: 543-552, 2009. 
28. Li Y, Chinni SR and Sarkar FH: Selective growth regulatory and pro-apoptotic effects of DIM is mediated by AKT and NF-kappaB pathways in prostate cancer cells. Front Biosci 10: $236-243,2005$

29. Xu Y,Zhang J, Shi W and Liu Y: Anticancer effects of 3,3'-diindolylmethane are associated with G1 arrest and mitochondria-dependent apoptosis in human nasopharyngeal carcinoma cells. Oncol Lett 5 655-662, 2013.

30. Roh YS, Cho A, Islam MR, Cho SD, Kim J, Kim JH, Lee JW, Lim CW and Kim B: 3,3'-Diindolylmethane induces immunotoxicity via splenocyte apoptosis in neonatal mice. Toxicol Lett 206: 218-228, 2011.
31. Anderton MJ, Manson MM, Verschoyle R, Gescher A, Steward WP, Williams ML and Mager DE: Physiological modeling of formulated and crystalline 3,3'-diindolylmethane pharmacokinetics following oral administration in mice. Drug Metab Dispos 32: 632-638, 2004. 